\title{
Kıvırcık koyunlarında anöstrus döneminde farklı senkronizasyon yöntemlerinin döl verimi üzerine etkisi*
}

\section{The effect of different synchronization methods on fertility in K1vircik sheep in anoestrus period}

\author{
Yağmur DUYMAZ®, Mehmet KOYUNCU® \\ Bursa Uludağ Üniversitesi, Ziraat Fakültesi, Zootekni Bölümü, Bursa \\ Sorumlu yazar (Corresponding author): M. Koyuncu, e-posta (e-mail): koyuncu@uludag.edu.tr \\ Yazar(lar) e-posta (Author e-mail): yagmurduymaz@gmail.com
}

\section{MAKALE BİGİSI}

Alınıs tarihi 25 Ocak 2021

Düzeltilme tarihi 04 Mayıs 2021

Kabul tarihi 04 Mayıs 2021

\section{Anahtar Kelimeler:}

Koyun

Senkronizasyon yöntemleri

Döl verimi

Yaşama gücü

\begin{abstract}
$\ddot{\mathbf{o z}}$
$\mathrm{Bu}$ araștırmada farklı senkronizasyon uygulamalarının koyunlarda döl verimi üzerine etkisi değerlendirilmiş ve 120 baş Kıvırcık koyun rastgele 4 uygulama ve 1 kontrol grubu olmak üzere 5 gruba ayrılmıştır. I. grup koyunlarda $18 \mathrm{mg}$ melatonin içeren Regülin implantı özel aplikatörü ile kulak arkası deri altına uygulanmıştır. II. gruba CIDR (Controlled Internal Drug Release) aparatı intravajinal olarak 12 süreyle yerleştirilmiş ve çıkarıldığı gün koyun başına 500 I.U. GKSH (Gebe Kısrak Serum Hormonu) kas içi olarak uygulanmıștır. III. gruba 20 mg flugeston asetat emdirilmiş süngerler 14 gün süreyle intravajinal olarak yerleştirilmiş ve çıkarıldığı gün koyun başına 500 IU GKSH kas içi olarak uygulanmıştır. IV. gruba 11 gün ara ile iki doz halinde deri altına $\mathrm{PGF}_{2 \alpha}$ (prostaglandin $\mathrm{F}_{2 \alpha}$ ) (3cc) enjeksiyonu uygulanmıştır. V. grupta ise herhangi bir uygulama yapılmamış kontrol grubu olarak değerlendirilmiştir. I., II., III., IV. ve V. grupta sirasıyla kuzulama oranı; $\% 80, \% 95, \% 88, \% 92$ ve $\% 76$; çoğuz doğum oranı; \%15.0, \%26.3, \%13.6, \%4.3 ve \%5.3; KKBDKS; $0.8,1.2,0.96,0.96$ ve 0.80 DKBDKS; $1.0,1.3,1.2,1.0$ ve 1.0 , yaşama gücü; $\% 88, \% 96, \% 96, \% 96$ ve $\% 90$ olarak tespit edilmiştir. Gebelik üretkenliği, gebelik etkinliği, toplam üretkenlik ve toplam etkinlik değerleri ise sürü genelinde sırasıyla; $453 \mathrm{~kg}, 7.9 \mathrm{~kg}, 2279 \mathrm{~kg}$ ve $40 \mathrm{~kg}$ olarak bulunmuştur. Uygulanan yöntemler içinde CIDR uygulaması ile diğerlerine göre daha verimli bir senkronizasyon elde edilebileceği görülmüştür.
\end{abstract}

\section{ARTICLE INFO}

Received 25 January 2021

Received in revised form 04 May 2021

Accepted 04 May 2021

\section{Keywords:}

Sheep

Synchronization methods

Fertility

Survival rate

\begin{abstract}
In this study, the effect of different synchronization applications on fertility in sheep was evaluated. One hundred twenty Kivırcık ewes were randomly allocated into five experimental groups as four treatments and one control group. In group I, the ewes were subcutaneously implanted with Regulin containing $18 \mathrm{mg}$ of melatonin with a special ear implant applicator. The ewes in group II, CIDR (Controlled Internal Drug Release) were inserted into vagina and removed after 12 days. Then 500 IU PMSG (Pregnant Mare Serum Gonadotropin) was injected intramuscularly to each ewe. The ewes in group III; $20 \mathrm{mg}$ flugeston acetate progestogen sponges were administered intravaginally for 14 days with intramuscular administration of $500 \mathrm{IU}$ PMSG at withdrawal time. The ewes in group IV, was injected subcutaneously with $\mathrm{PGF}_{2 \alpha}$ (prostaglandin $\mathrm{F}_{2 \alpha}$ ) $(3 \mathrm{cc}$ ) in two doses with an interval of 11 days. The ewes in group $\mathrm{V}$, no hormone treatment was applied and therefore evaluated as the control group. The results in the treatment and control groups, were $80 \%, 95 \%, 88 \%, 92 \%$ and $76 \%$ for lambing rates; $15.0 \%, 26.3 \%, 13.6 \%, 4.3 \%$ and $5.3 \%$ for multiple birth rates; $0.8,1.2,0.96$, 0.96 and 0.80 for fecundity; $1.0,1.3,1.2,1.0$ and 1.0 for litter size; $88 \%, 96 \%, 96 \%, 96 \%$ and $90 \%$ for survival rates, respectively. Gestation productivity, gestation efficiency, total productivity and overall efficiency values were found to $453 \mathrm{~kg}, 7.9 \mathrm{~kg}, 2279 \mathrm{~kg}$ and $40 \mathrm{~kg}$ respectively in the herd. Among the methods applied, it has been observed that a more efficient synchronization can be achieved with the CIDR application compared to the others.
\end{abstract}




\section{Giriş}

Koyun yetiştiriciliğinde, diğer hayvan türlerinde olduğu gibi, işletmelerin sürdürülebilirliği (sosyal/ekonomik) öncelikle döl verimi ile ilişkilidir. $\mathrm{Bu}$ üretim kolunda üreme potansiyelinin optimum düzeyde tutulması için özellikle birim hayvandan daha fazla yavru alınması, çoğuz doğumun artırılması ve yılda iki ya da iki yılda üç doğum planlanması gibi yönetsel uygulamalar döl veriminin iyileştirilmesinde kullanılmaktadır. Kızgınlıkların toplulaştırılmasında hem üreme mevsiminde hem de üreme mevsimi dışında progesteron ve analoglarının kullanımı yaygındır. Bu uygulamalar, 5-6 gün gibi kısa süreli veya 12-14 gün gibi uzun süreli olabilmektedir. Progesteron ve analoglarının ardından gebe kısrak serum hormonu uygulanmaktadır. Prostaglandin $\mathrm{F}_{2 \alpha}$ ve analogları ile luteolizisin uyarılması, özellikle üreme mevsiminde döl veriminin denetlenmesi için alternatif bir yöntemdir. Üreme mevsimindeki koyunlara 9-10 gün arayla iki kez $\mathrm{PGF}_{2 \alpha}$ enjekte edildiğinde hayvanların \%95'i ikinci dozdan sonraki 72 saat içerisinde kızgınlık göstermektedir (Mirzaei ve ark. 2017). Diğer taraftan epifiz bezi hormonu olan melatoninin koyunlarda üreme mevsiminin kontrolündeki önemi ile oral, intravajinal, enjektabl veya derialtı yöntemler ile uygulamanın çeşitli avantajlar sağladığı ortaya konmuştur (Kaya ve ark. 2003).

Yumurtlamanın gerçekleşmediği koyunlarda döngüsel aktivite uyarıldıktan sonra, mevsimsel üreme manipüle edilebilir ve üretim döngüsü kısaltılabilir. $\mathrm{Bu}$ uygulamaların küçükbaş hayvanlarda sağladığı ikinci bir firsat ise, birçok ırkın çoğuz yavruları taşıma ve büyütme eğilimidir. $\mathrm{Bu}$, genellikle kızgınlık senkronizasyonu uygulamasının bir parçası olarak hormonların doz seviyelerinde ayarlamalar ve besleme manipülasyonları ile kontrol edilebilir (Wildeus 2000). Bu noktalar göz önüne alındığında yapılacak olan çeşitli biyoteknolojik uygulamalar koyunlarda kızgınlığın saptanması ve gebe bırakma noktasında oluşabilecek dezavantajın giderilmesinin yanı sıra kârlılık da sağlayacaktır. Son yıllarda biyoteknolojik uygulamalar kapsamında değerlendirilen ve buna bağlı birçok uygulama alanının ortaya çıkmasını sağlayan kızgınlığı uyarılması ve senkronize edilmesi yoluyla, mevsim dışı yavru üretimi ve yem kaynaklarının daha iyi kullanımının yanısıra, mevsime bağlı oluşabilecek etkilenmeleri en aza indirebilecek koşullar oluşturulabilmekte ve turfanda kuzu üretimi de sağlanmış olmaktadır. Aşımların toplulaştırılarak kuzulamaların kısa sürede bitirilmesi ile bakım ve besleme, iş gücü, barınak ve diğer kaynakların kullanımında önemli avantajlar elde edilebilmektedir. Bu çalışmada, Kıvırcık ırkı koyunlarda üreme mevsimi dışındaki dönemde flugeston asetat emdirilmiş sünger, CIDR, melatonin implantları ve $\mathrm{PGF}_{2 \alpha}$ enjeksiyonları ile kızgınlığın senkronize edilerek, bazı üreme parametreleri için yöntemler arası karşılaştırılma yapılması amaçlanmıştır.

\section{Materyal ve Yöntem}

Araştırmada, Bursa Uludağ Üniversitesi Ziraat Fakültesi Araştırma Uygulama Çiftliği'ne bağlı Koyunculuk İşletmesi'nde yetiştirilen daha önce doğum yapmış 3-4 yaşlı 45-60 kg canlı ağırlığında ve mevsimsel anöstrus döneminde olan 120 baş Kıvırcık koyun ve 8 baş ergin damızlık koç kullanılmıştır. Bu çalışma Bursa Uludağ Üniversitesi Hayvan Deneyleri Yerel Etik Kurulu'nun onayı ile (2017-10/01) yürütülmüştür.

Değerlendirmeye alınan koyunlarda kızgınlığın toplulaştırılması uygulamaları üreme mevsimi dışı olarak değerlendirilen haziran-temmuz ayları içinde gerçekleştirilmiştir. Araştırma sürüsü 5 farklı uygulama grubuna ayrılarak uygulamalar yönteme bağlı olarak izlenmiştir (Çizelge $1)$.

Deneme gruplarında serbest koç katımı uygulanmışıtır. Koçlar sürüde yaklaşık üç dönemi kapsayacak şekilde 45 gün tutulmuştur. Koyunlarda koç katımı uygulamalar sonunda tüm gruplarda aynı zaman diliminde başlayıp bitecek şekilde planlanmıştır.

Araştırmanın yürütüldüğü haziran-ocak ayları arasında hava koşullarının iyi olduğu dönemlerde sürü gündüz meraya çıkarılmış, akşam ağıla alınmıştır. Koyunların merada tutulma süreleri, meranın ot kapasitesi ve işgücü gibi kriterlere göre çalışma süresince (koç katım, gebelik, doğum) koyunlardan daha iyi performans alınması amacıyla ek yemleme yapılmıştır. Koyunlara yaklaşı $1 \mathrm{~kg} \mathrm{baş}^{-1}$ kuru ot ve 300-600 $\mathrm{g} \mathrm{baş}^{-1}$ işletmede hazırlanan yoğun yem verilmiş, su ve mineral kaynağa (yalama taşı) serbest olarak ulaşmaları sağlanmıştır. Doğumlar aralık-ocak aylarında tamamlanmıştır. Kuzuların doğumu takip eden ikinci haftaya kadar analarından süt emmeleri sağlanmış, bu dönemden sonra ise creep feeding adı verilen uygulama ile istedikleri zaman kaliteli kaba yem (yonca) ve kuzu büyütme yemi alabilmelerine veya analarının yanına gidip onları emmelerine uygun bir sisteme geçilmiştir.

Araştırmada kuzulama, kısırlık, çoğuz doğum, yaşama gücü oranları (doğum-sütten kesim) ve koçaltı koyun başına doğan kuzu sayısı (KKBDKS) ile doğuran koyun başına doğan kuzu sayıları (DKBDKS) yanı sıra gebelik üretkenliği, gebelik etkinliği, toplam üretkenlik ve toplam etkinlik değerleri hesaplanmıştır (Sönmez ve Kaymakçı 1987).

Farklı senkronizasyon uygulama gruplarında döl verimi özelliklerinin karşılaştırılmasında $\chi^{2}$ (Ki-kare) analiz yönteminden yararlanılmış, analizlerde ise Minitab 17.0 paket programı kullanılmışır (Minitab 2014).

\section{Bulgular ve Tartışma}

Kızgınlık senkronizasyonu ile meraların koyun tarafindan daha az kullanılması, kontrollü çiftleşmenin daha iyi planlanması, yetiştirme uygulamalarının düzenlenmesi ve benzer yaşta kuzu üretilmesi gibi yönetsel firsatlar sunmaktadır (Godfrey ve ark. 1997; Niasari-Naslaji ve Soukhtezari 2005). $\mathrm{Bu}$ amaçla üremenin kontrolü için uygulanacak hormanal uygulamalar, işletmelerde arzu edilen üreme başarısının elde edilmesi ve gebeliğin arttırılması noktasında bir önkoşuldur. $\mathrm{Bu}$ çalışmada yukarıda bahsedilen amaçlar doğrultusunda koyunculuk işletmelerinde kızgınlığın senkronizasyonuna yönelik sıklıkla uygulanan yöntemler birlikte değerlendirilmiştir. Kıvırcık koyunlara üreme mevsimi dışında uygulanan dört farklı yöntemin döl verim özellikleri sonuçları Çizelge 2'de verilmiştir. Koyunlara takılan sünger ve CIDR aparatlarından sadece bir koyunda CIDR aparatının atıldığ 1 saptanmıştır.

Kuzulama oranı, CIDR grubunda diğer uygulamalardan daha yüksek olmasına rağmen farklı yöntemler arasında anlamlı bir fark bulunmamıştır $(P>0.05)$. deNicolo ve ark. (2008) ise progesteron + GKSH'ye ek olarak melatonin uygulanan koyunların, progesteron ve GKSH uygulananlara göre daha yüksek gebelik ve kuzulama oranına sahip olduğunu bildirmiştir. Diğer taraftan, GKSH'nin yokluğunda, melatoninin, koyunlara progesteron ile verilse bile mevsim dışı üreme aktivitesini başlatmada yetersiz kaldığı gözlemlenmiştir. Araştırmada CIDR uygulanan gruptan elde edilen \%95 
Çizelge 1. Uygulama grupları ve hayvan sayıları

Table 1. Treatment groups and animal numbers

\begin{tabular}{|c|c|c|c|}
\hline Gruplar & Yöntem & Koyun sayısı (baş) & Uygulama \\
\hline 1 & Melatonin & 25 & $\begin{array}{l}18 \text { mg melatonin içeren Regülin implantı özel aplikatörü ile kulak arkası deri altına } \\
\text { uygulanmıştır. Uygulama yapıldıktan } 35 \text { gün sonra koç katımı gerçekleştirilmiştir. }\end{array}$ \\
\hline 2 & $\mathrm{CIDR}+\mathrm{GKSH}$ & 20 & $\begin{array}{l}\text { CIDR aparatı ( } 0.33 \text { g silikona emdirilmiş progesteron) vajina içi araç ile intravajinal } \\
\text { olarak yerleştirilmiş, 12. günde çıkartılmış ve aynı gün koyun başına } 500 \text { IU GKSH } \\
\text { kas içi olarak uygulanmıştır. Uygulamayı takip eden } 24 \text { saat içinde koç katımı } \\
\text { gerçekleştirilmiştir. }\end{array}$ \\
\hline 3 & Sünger + GKSH & 25 & $\begin{array}{l}20 \text { mg FGA emdirilmiş süngerler (Chronogest CR) intravajinal olarak yerleştirilmiştir. } \\
\text { Süngerler 14. günde çıkartılmış ve aynı gün koyun başına } 500 \text { IU GKSH kas içi olarak } \\
\text { uygulanmıştır. Uygulamayı takip eden } 24 \text { saat içinde koç katımı gerçekleştirilmiştir. }\end{array}$ \\
\hline 4 & $\mathrm{PGF}_{2 \alpha}$ & 25 & $\begin{array}{l}11 \text { gün ara ile iki doz halinde deri altına prostaglandin } \mathrm{F}_{2 \alpha}(3 \mathrm{cc}) \text { enjeksiyonu } \\
\text { uygulanmıştır. Uygulamayı takip eden } 48 \text { saat içinde koç katımı gerçekleştirilmiştir. }\end{array}$ \\
\hline 5 & Kontrol & 25 & $\begin{array}{l}\text { Koyunlara herhangi bir uygulama yapılmamış ve diğer gruptakiler ile birlikte koç } \\
\text { katımına alınmıştır. }\end{array}$ \\
\hline
\end{tabular}

Çizelge 2. Farklı kızgınlık senkronizasyon yöntemlerinde koyunların üreme performansı

Table 2. Reproductive performance of sheep in different estrus synchronization methods

\begin{tabular}{|c|c|c|c|c|c|c|}
\hline \multirow[b]{2}{*}{ Üreme Parametreleri } & \multicolumn{5}{|c|}{ Yöntemler } & \multirow[b]{2}{*}{$\chi^{2}$} \\
\hline & Melatonin & CIDR & Sünger & $\mathrm{PGF}_{2 \alpha}$ & Kontrol & \\
\hline Koyun sayısı (n) & 25 & 20 & 25 & 25 & 25 & \\
\hline Kuzulama Oranı (\%) & $\begin{array}{c}80 \\
(20 / 25)\end{array}$ & $\begin{array}{c}95 \\
(19 / 20)\end{array}$ & $\begin{array}{c}88 \\
(22 / 25)\end{array}$ & $\begin{array}{c}92 \\
(23 / 25)\end{array}$ & $\begin{array}{c}76 \\
(19 / 25)\end{array}$ & $\begin{array}{c}0.380 \\
P>0.05\end{array}$ \\
\hline Kisırlık oranı (\%) & $\begin{array}{c}20 \\
(5 / 25)\end{array}$ & $\begin{array}{c}5 \\
(1 / 20)\end{array}$ & $\begin{array}{c}12 \\
(3 / 25)\end{array}$ & $\begin{array}{c}8 \\
(2 / 25)\end{array}$ & $\begin{array}{c}24 \\
(6 / 25)\end{array}$ & \\
\hline Çoğuz doğum oranı (\%) & $\begin{array}{c}15.0 \\
(3 / 20)\end{array}$ & $\begin{array}{c}26.3 \\
(5 / 19)\end{array}$ & $\begin{array}{c}13.6 \\
(3 / 22)\end{array}$ & $\begin{array}{c}4.3 \\
(1 / 23)\end{array}$ & $\begin{array}{c}5.3 \\
(1 / 25)\end{array}$ & $\begin{array}{c}5.715 \\
P>0.05\end{array}$ \\
\hline Koç altı koyun başına doğan kuzu sayısı & 0.8 & 1.2 & 0.96 & 0.96 & 0.80 & \\
\hline Doğuran koyun başına doğan kuzu sayısı & 1.0 & 1.3 & 1.2 & 1.0 & 1.0 & \\
\hline Yaşama gücü (\%) & 88 & 96 & 96 & 96 & 90 & $\begin{array}{c}0.058 \\
P>0.05\end{array}$ \\
\hline
\end{tabular}

kuzulama oranı, Knights ve ark. (2001)'nın 5 gün süreyle CIDR ile 5 gün süreyle CIDR ve FSH uygulamasında sirasıyla $\% 70$ ve $\% 66$, Ungerfeld ve Rubiones (2002)'in 6 gün süreyle CIDR ve 380 IU GKSH uygulamasında \%59.6, Dixon ve ark. (2006)'nın 12 gün süreyle iki CIDR uygulamasında \%79.1, Yadi ve ark. (2011)'nın 12 gün süreyle CIDR ve 500 IU GKSH uygulamasında $\% 45$, Swelum ve ark. (2015)'nın 14 gün süreyle CIDR ve 600 IU GKSH uygulamasında \%75.57, Ezzat ve ark. (2016)'nın 12 gün süreyle CIDR ve 400 IU GKSH uygulamasında \%85.7 olarak belirlediği kuzulama oran1 değerlerinden yüksek; Carlson ve ark. (1989)'nın 12 gün süreyle CIDR uygulanan grupta bulduğu $\% 95$ değerine benzer; Altınçekiç ve Koyuncu (2017)'nun Kıvırcık koyunlarında 14 gün süreyle CIDR ve 300 IU GKSH uygulanan grupta belirlediği $\% 100$ kuzulama oranı değerinden düşük bulunmuştur. $\mathrm{Bu}$ çalışmaya benzer şekilde sünger+GKSH uygulaması ile farklı ırklar üzerinde yürütülen çalışmalarda elde edilen kuzulama oranları; Miljkovic ve ark. (1989) tarafindan $30 \mathrm{mg}$ FGA sünger ve $500 \mathrm{IU}$ GKSH enjeksiyonuyla \%85, Daşkın (2001) tarafından 30 mg FGA süngeri ve 500 IU GKSH enjeksiyonuyla \%92.30, Koyuncu ve ark. (2001) tarafindan 14 gün süreyle $40 \mathrm{mg}$ FGA süngeri ve 500 IU $\mathrm{GKSH}$ uygulamasiyla \%96.6, Swelum ve ark. (2015) tarafindan $20 \mathrm{mg}$ FGA süngeri ve 600 IU GKSH uygulamasıla \%60.99, Ezzat ve ark. (2016) tarafindan $20 \mathrm{mg}$ FGA süngeri ve $400 \mathrm{IU}$ GKSH uygulamasiyla \%71.4 olarak tespit edilmiştir. Prostaglandin $F_{2 \alpha}$ ve analogları kızgınlığın luteal fazı üzerine etkilidir. $\mathrm{PGF}_{2 \alpha}$ uygulanan hayvanların tümü kızgınlık döngüsünün luteal fazında olduğunda tek bir enjeksiyon yeterli olabilir. Ancak luteal fazın takibinin yapılmadığı ve sürüde rastgele uygulama yapıldığı durumlarda luteal fazda olmayan koyunlarda senkronizasyon başarısız olmaktadır. Bu nedenle farklılıkların önüne geçilebilmesi için 9-11 gün arayla iki doz Prostaglandin $F_{2 \alpha}$ uygulanmaktadır (Beck ve ark. 1993). Prostaglandin $F_{2 \alpha}$ grubundaki \%92 kuzulama oranı değeri, üreme mevsimi dışında iki doz PGF $_{2 \alpha}$ uygulayan Mirzaei ve ark. (2017)'nın \%90 olarak bildirdiği doğum oranına benzer; 11 gün arayla iki doz $\mathrm{PGF}_{2 \alpha}$ uygulayan Öztürkler ve ark. (2003)'nın bildirdiği \%53.7, 9 gün arayla iki doz $125 \mu \mathrm{g}$ veya $250 \mu \mathrm{g}$ uygulayan Kumar ve ark. (2018)'nın bildirdiği sırasıyla, \%71.43 ve \%66.67 değerlerinden yüksek bulunmuştur. $\mathrm{Bu}$ yüksekliğin nedeni $\mathrm{PGF}_{2 \alpha}$ dozunun farklı olmasına ve uygulama zamanının kızgınlık döngüsünün farklı evrelerine denk gelmesine bağlanabilir. Fitzgerald ve ark. (1985) $\mathrm{PGF}_{2 \alpha}$ ile 7 gün süreyle intravajinal MAP (Medroksiprogesteron Asetat) uygulamasının, yalnızca progesteron veya $\mathrm{PGF}_{2 \alpha}$ uygulamasından kızgnlık senkronizasyonu için daha etkili olduğunu bildirmiştir. Yaprak ve Korkmaz (2016) Morkaraman koyunlarında farklı senkronizasyon uygulamalarından CIDR, progesteron ve MAP için kuzulama oranı değerlerini sırasıyla; \%74, \%56 ve \%33 $(P>0.01)$ olarak bildirmiştir. Farklı senkronizasyon yöntemlerinin yanı sıra, farklı 1rk ve yaştaki hayvanların kullanımının veya besleme faktörlerinin gebelik oranlarını buna bağlı olarak kuzulama oranlarını etkilemesi kaçınılmazdır.

Çoğuz doğum oranı, doğru ve karlı bir kuzu üretimi için vazgeçilmez bir öneme sahiptir. CIDR, melatonin ve sünger gruplarındaki çoğuz doğum oranları $\mathrm{PGF}_{2 \alpha}$ ve kontrol grubuna göre daha yüksek bulunmasına karşın, uygulama grupları arasında istatistiki olarak anlamlı bir fark bulunmamıştır $(P>0.05)$. Melatonin uygulanan grupta \%15 olarak bulunan çoğuz doğum oranı; Kaya ve ark. (2003)'nın melatonin ile melatonin ve MAP sünger uygulanan gruplarda sirasiyla, \%52.9 
ve \%73.7 olarak belirlediği değerlerden düşüktür. Bazı araştırmacılar (Wallace ve ark. 1988; Haresign ve ark. 1990; Durotoye ve ark. 1991; Abecia ve ark. 2002) yaptıkları çalışmalarda melatonin uygulanan gruplardaki ikizlik oranının yüksekliğini, melatonin hormonunun gonadotropik etkisine ve buna bağlı olarak yumurtlama oranını artırmasına ve luteotropik etki ile embriyonik yaşamı olumlu etkilemesine bağlamışlardır. Uygulama grupları içinde en yüksek CIDR grubunda görülen \%26.3'lük çoğuz doğum oranı, Yadi ve ark. (2011)'nın bildirdiği \%11 değerinden yüksek; Swelum ve ark. (2015)'nın \%34.34, Altıçekiç ve Koyuncu (2017)'nun \%50 olarak bildirdiği değerlerden düşük bulunmuştur. Greyling ve van Niekerk (1990) üreme mevsimi dişında yapılacak senkronizasyon uygulamalarında folliküler büyümenin desteklenmesi ve yüksek yumurtlama oranı için PMSG enjeksiyonu ile desteklenmesi gerektiğini bildirmişlerdir. $\mathrm{Bu}$ çalışmada PMSG uygulanan gruplarda yüksek çoğuz doğum oranı gözlenmesi bu durumu desteklemektedir. Koyuncu ve ark. (2001), üreme mevsiminde 40 mg FGA sünger + 500 IU GKSH uygulamasında çoğuz doğum oranını \%44.82 olarak bulmuşlardır. Bacha ve ark. (2014), 7 gün süreyle 40 mg FGA ve bitiminde 500 IU GKSH uygulaması ile bu araştırmaya benzer protokol uygulamışlar ve ikizlik oranını \%40 olarak bildirmişlerdir. PGF $2 \alpha$ uygulama grubunda elde edilen çoğuz doğum oranı, üreme mevsimi içerisinde 10 gün arayla çift doz $\mathrm{PGF}_{2 \alpha}$ uygulayan Mirzaei ve ark. (2017)'nın bildirdiği \%40.7, 11 gün arayla çift doz uygulayan Yadi ve ark. (2011)'nın bulduğu \%14, üreme mevsimi dişında tek doz $\mathrm{PGF}_{2 \alpha}$ ve $300 \mathrm{IU}$ GKSH uygulayan Altınçekiç ve Koyuncu (2017) tarafindan bildirilen \%30 ikizlik oranı değerinden düşük; 10 gün arayla çift doz uygulayan Abdalla ve ark. (2014)'nın \%5.26 olarak bulduğu değere yakındır.

KKBDKS ve DKBDKS değerleri melatonin, CIDR, sünger, $\mathrm{PGF}_{2 \alpha}$ ve kontrol gruplarında sirasiyla, $0.8,1.2,0.96,0.96,0.80$ ve $1.0,1.3,1.2,1.0$ ve 1.0 olarak belirlenmiştir. Ak ve ark. (1995), Kıvırcık koyunlarında dört farklı senkronizasyon yöntemi uygulaması sonucunda doğuran koyun başına doğan kuzu sayısını sirasiyla; $1.53,1.78,1.56$ ve 1.38 olarak bildirmiştir. Laliotis ve ark. (1998) $18 \mathrm{mg}$ melatonin implant grubunda DKBDKS 1.48; Nowers ve ark. (1994) 1.13 olarak araştırma sonucundan yüksek bulmuşlardır. Kridli ve ark. (2006) yalnızca melatonin uygulanan grupta KKBDKS 0.6 ve DKBDKS 1.0 ve melatonin ve FGA süngerlerin birlikte kullanıldığ 1 grupta KKBDKS ve DKBDKS değeri sırasıyla; 0.8 ve 1.0 dir. Gómez ve ark. (2004), üreme mevsimi dişında uyguladıkları melatonin implantları ve progesteron + GKSH sonucunda DKBDKS 1.55 ve 1.50 olarak yakın bulunması iki uygulama yönteminin de benzer sonuçlar sağladığını göstermiştir. Knights ve ark. (2001) yalnıza CIDR ile CIDR ve FSH uygulanan gruplarda sırasıyla 1.50 ve 1.66 olarak araştırma sonuçlarına göre yüksek değerler elde etmişlerdir. Knights ve ark. (2001) CIDR uygulamasının bitiminde ve bitiminden 18 saat önce tek doz $\mathrm{PGF}_{2 \alpha}$ uygulamalarında her iki yöntem için de DKBDKS 1.69; Beck ve ark. (1993) 11 gün arayla çift doz $\mathrm{PGF}_{2 \alpha}$ uygulamasında elde ettikleri 1.5 değeri bu araştırmada bulunan değerden yüksektir. Karakuş ve Aşkın (2007), Anadolu Merinosu ve Malya koyunları üzerinde yaptıkları çalışmada 40 mg FGA süngerler 14 gün sonunda çıkarılmış ve $500 \mathrm{IU}$ GKSH kas içi enjekte edilmiştir. Elde edilen KKBDKS ve DKBDKS Anadolu Merinosu için 1.41 ve 1.50; Malya koyunu için 1.45 ve 1.54 olarak bulmuşlardır. Altınçekiç ve Koyuncu (2017) ise tek doz PGF $_{2 \alpha}$ uygulaması sonucunda KKBDKS 1.3 olarak; Dixon ve ark. (2006) DKBDKS 1.80 olarak araştırma sonucundan yüksek bulmuşlardır.

Kuzuların yaşama gücü, işletmedeki koyunların üreme verimliliğini ortaya koyan önemli bir gösterge olmanın yanında, refah ile birlikte değerlendirildiğinde sürülerin gelişimi, verimliliği ve sürdürülebilirliğinin temel faktörleri arasında da yer aldığı ifade edilmektedir (Mellor ve Stafford 2004). Araştırma materyali kuzularda yaşama gücü melatonin, CIDR, sünger, $\mathrm{PGF}_{2 \alpha}$ ve kontrol grupları için sırasılla $\% 88, \% 96, \% 96$, $\% 96$ ve \%90 olarak bulunmuştur. Yaşama gücü bakımından farklı senkronizasyon grupları arasındaki fark istatistiki olarak önemsiz olmuştur $(P>0.05)$. Kıvırcık koyunları için yaşama gücünü Ceyhan ve ark. (2007) 120. günde \%97 olarak bulmuşlardır. Altınçekiç ve Koyuncu (2017) ise CIDR ve prostaglandin $\mathrm{F}_{2 \alpha}$ 'nın uygulandığ 1 gruplarda yaşama gücünü her iki grup için $\% 100$ olarak saptamışlardır.

Araştırmada farklı senkronizasyon yöntemlerine göre gebelik üretkenliği, gebelik etkinliği, toplam üretkenlik ve toplam etkinlik değerleri Çizelge 3'de verilmiştir. Uygulama grupları içinde sözkonu parametreler açısından en yüksek değerler CIDR grubunda elde edilmiştir. Gebelik üretkenliği kontrol grubu dışında kalan gruplarda ortalama $517.3 \mathrm{~kg}$ olup, Kıvırcık ve Norduz koyunları için bildirilen sırasıyla, 510.0 ve $517.71 \mathrm{~kg}$ değerlerine yakın (Karakuş ve Cengiz 2007; Koyuncu ve Akgün 2018); Karakaş ve Norduz koyunlarında bulunan sırasıyla 481.5 ve $487.7 \mathrm{~kg}$ değerlerinden yüksek (Ülker ve ark. 2004); Tahirova, Doğu Friz x İvesi ve Menemen koyunları için bildirilen sırasıly $730 \mathrm{~kg}, 521 \mathrm{~kg}$ ve $564 \mathrm{~kg}$ değerlerinden düşük bulunmuştur (Demirören 2002). Bu çalışmadaki toplam üretkenlik değeri ise Tahirova, Menemen, Doğu Friz x İvesi ve Kıvırcık koyunları için bildirilen değerlere benzerdir (Demirören 2002; Koyuncu ve Akgün 2018). Y1lmaz (2017), Kıvırcık koyunlarında gebelik üretkenliği, gebelik etkinliği, toplam üretkenlik ve toplam etkinlik değerlerini sirasiyla $368 \mathrm{~kg}, \quad 7.56 \mathrm{~kg}, \quad 2304 \mathrm{~kg}$ ve $47.38 \mathrm{~kg}$ olarak bildirmiştir.

Çizelge 3. Farklı yöntemlerin uygulandığı koyunlarda gebelik üretkenliği, gebelik etkinliği, toplam üretkenlik ve toplam etkinlik değerleri (kg) Table 3. Gestation productivity, gestation efficiency, total productivity and overall efficiency values ( $\mathrm{kg}$ ) in sheep using different methods

\begin{tabular}{lrrrrrr}
\hline \multirow{2}{*}{ Üreme Parametreleri } & \multicolumn{9}{c}{ Yöntemler } \\
\cline { 2 - 7 } & Melatonin & CIDR & Sünger & \multicolumn{1}{c}{ PGF $_{2 \alpha}$} & Kontrol & Genel \\
\hline Gebelik Üretkenliği & 525 & 552.6 & 501.8 & 489.6 & 461.1 & 453 \\
Gebelik Etkinliği & 8.1 & 9.5 & 8.3 & 9.3 & 5.3 & 7.9 \\
Toplam Üretkenlik & 2555 & 3185.6 & 2789.5 & 2161.3 & 2072.6 & 2279 \\
Toplam Etkinlik & 39.6 & 55 & 46.3 & 41 & 24 & 40 \\
\hline
\end{tabular}




\section{Sonuç}

Kızgınlık senkronizasyonu uygulamaları, kuzulama aralığını azalttığ1 ve özellikle küçükbaş hayvanlarda mevsimden bağımsız olarak ele alınabildiği için, yıl içinde farklı zamanlarda yavru alınmasını sağlayabilmektedir. Bu çalışmada koyunlarda üreme mevsimi dışında farklı kızgınlık senkronizasyon yöntemlerinin döl verimi üzerinde istenilen etkiyi oluşturduğu ancak gruplar arasında istatistiki olarak anlamlı bir farklılık olmadığı belirlenmiştir. Uygulan yöntemler kapsamında CIDR aygitı ve 500 IU GKSH enjeksiyonu ile verimli bir senkronizasyon elde edilebileceği görülmüştür. Diğer taraftan sünger ve CIDR aygitlarının takılma ve çıkarılması sırasında oluşabilecek vajinal enfeksiyonlar göz önüne alındığında, maliyeti daha düşük $\mathrm{PGF}_{2 \alpha}$ enjeksiyon uygulamasının bu tip problemlerin önüne geçmesi beklenebilir. Kızgınlık senkronizasyonunun avantajları uygun önemler alınmadığı durumlarda dezavantaja dönüşebilmektedir. Kızgınlıkların görülmeye başladığı zamanın kısa sürede ortaya çıkması, sürüde fazla sayıda fertil koç bulunmasını gerekli kılmaktadır. Bunun yanı sıra üreme mevsimi dışında yapılan kuzulatmalarda doğumların kış dönemine rastlaması durumunda, eğer barınma ve beslenme koşulları da yetersiz ise fazla sayıda kuzu kayıplarının yaşanması kaçınılmaz olacaktır. İşletmelerin uygulayacakları yöntemleri seçerken uygulamanın yapılacağı mevsim, koyunların fizyolojik durumları, 1rk1, işletmenin üretim hedefi, bakım-besleme-barınma koşulları, sermayesi ve bölgedeki ürün talebi dikkate alınmalıdır.

\section{Kaynaklar}

Abdalla EB, Farrag B, Hashem ALS, Khalil FA, Abdel-Fattah MS (2014) Effect of progestagen, PGF2 $\alpha$, PMSG and GnRH on estrus synchronization and some reproductive and productive traits in Barki ewes. Journal of Agroalimentary Processes and Technologies 20(1): 93-101.

Abecia JA, Forcada F, Zúñiga O (2002) The effect of melatonin on the secretion of progesterone in sheep and on the development of ovine embryos in vitro. Veterinary Research Communications 26: 151158.

Ak K, Horoz H, İleri K, Alkan S, Boran A, Öztürkler Y, Çörekçi Ş (1995) Kıvırcık koyunlarında aşım mevsimi ve anöstrus döneminde progestagen-pg2 $\alpha$ kombinasyonu ile östrus senkronizasyonu. Hayvancılık Araştırma Dergisi 5(1-2): 74-76.

Altınçekiç ŞÖ, Koyuncu M (2017) Anöstrustaki kıvırcık ırkı koyunlarda cidr ve prostaglandin uygulamalarının üreme performansı üzerine etkilerinin karşılaştırılması. Tekirdağ Ziraat Fakültesi Dergisi 14(1): 9-15.

Bacha S, Khiati B, Hammoudi SM, Kaidi R, Ahmed M (2014) The effects of dose of pregnant mare serum gonadotropin (PMSG) on reproductive performance of Algerian Rembi ewes during seasonal anoestrus. Journal Veterinary Science Technology 5(4):1-3.

Beck NFG, Davies B, Williams SP (1993) Oestrous synchronization in ewes: the effect of combining a prostaglandin analogue with a 5day progestagen treatment. Animal Science 56(2): 207-210.

Carlson KM, Pohl HA, Marcek JM, Muser RK, Wheaton JE (1989) Evaluation of progesterone controlled internal drug release dispensers for synchronization of estrus in sheep. Animal Reproduction Science 18: 205-218.

Ceyhan A, Erdoğan İ, Sezenler T (2007) Gen kaynağı olarak korunan Kıvırcık, Gökçeada ve Sakız koyun ırklarının bazı verim özellikleri. Tekirdağ Ziraat Fakültesi Dergisi 4(2): 211-218.

Daşkın A (2001) Östrusları sinkronize edilen Akkaraman koyunlarında PMSG enjeksiyonlarının dölverimine etkisi. Ankara Üniversitesi Veteriner Fakültesi Dergisi 48(2):165-167.
Demirören E (2002) Yetiştirme amacı farklı koyunlarda kuzu üretim etkinliği. Ege Üniversitesi Ziraat Fakültesi Dergisi 39(1): 71-77.

deNicolo G, Morris ST, Kenyon PR, Morel PCH, Parkinson TJ (2008) Melatonin-improved reproductive performance in sheep bred out of season. Animal Reproduction Science 109(1-4): 124-133.

Dixon AB, Knights M, Pate JL, Lewis PE, Inskeep EK (2006) Reproductive performance of ewes after 5-day treatment with intravaginal inserts containing progesterone in combination with injection of prostaglandin F2 $\alpha$. Reproduction in Domestic Animals 41(2): 142-148.

Durotoye LA, Rajkumar R, Argo CM, Nowak R, Webley GE, McNeil ME, Graham NB, Rodway RG (1991) Effect of constant-release melatonin implants on the onset of oestrous activity and on reproductive performance in the ewe. Animal Science 52(3): 489497.

Ezzat AA, Ahmed MN, Elabdeen MA, Sabry AM (2016) Estrus synchronization in Ossimi sheep by progestins. Alexandria Journal of Veterinary Sciences 51(1): 207-214.

Fitzgerald JA, Ruggles AJ, Stellflug JN, Hansel W (1985) A seven-day synchronization method for ewes using medroxyprogesterone acetate (MAP) and prostaglandin F2 $\alpha$. Journal of Animal Science 61(2): 466-469.

Godfrey RW, Gray ML, Collins JR (1997) A comparison of two methods of oestrus synchronization in hair sheep in the tropics. Animal Reproduction Science 47: 99-106.

Gómez JD, Balasch S, Gómez LD, Martıno A, Fernández N (2004) Comparison between intravaginal progestagen and melatonin implant treatments on the reproductive efficiency of ewes. Small Ruminant Research 66(1-3): 156-163.

Greyling JPC, Van Niekerk CH (1990) Effect of pregnant mare serum gonadotrophin (PMSG) and route of administration after progestagen treatment on oestrus and LH secretion in the Boer goat. Small Ruminant Research 3(5): 511-516.

Haresign W, Peters AR, Staples LD (1990) The effect of melatonin implants on breeding activity and litter size in commercial sheep flocks in the UK. Animal Science 50(1): 111-121.

Karakuş K, Aşkın Y (2007) Anadolu Merinosu ve Malya koyunlarında kızgınlığın toplulaştırılması ve bazı döl verimi özellikleri. Yüzüncü Y1l Üniversitesi Tarım Bilimleri Dergisi 17(1): 17-20.

Karakuş K, Cengiz F (2007) Ergin Norduz ve Karakaş koçlarında spermatolojik özelliklerin döl verimine etkisi. Yüzüncü Y1l Üniversitesi Tarım Bilimleri Dergisi 17(1): 7-15.

Kaya HH, Kaşıkçı G, Ak K, Alkan S, Sönmez C (2003) Controlling the breeding season using melatonin and progestagen in Kivircık Ewes. Turkish Journal of Veterinary Animal Sciences 27(2): 301-305.

Knights M, Maze TD, Bridges PJ, Lewis PE, Inskeep EK (2001) Shortterm treatment with a controlled internal drug releasing (CIDR) device and FSH to induce fertile estrus and increase prolificacy in anestrous ewes. Theriogenology 55(5): 1181-1191.

Koyuncu M, Uzun ŞK, Şengül L (2001) Synchronization of Oestrus and the Possibilities of Improving Reproductive Performance by using Progestagen and Different Doses of PMSG in Kivircik Ewes. Turkish Journal of Veterinary Animal Sciences 25(6): 971-974.

Koyuncu M, Akgün H (2018) Ekstansif yetiştirme koşullarındaki Kıvırcık koyunlarında bazı döl verimi özellikleri. Hayvansal Üretim Dergisi 59(1): 33-40.

Kridli RT, Husein MQ, Muhdi HA, Al-Khazaleh JM (2006) Reproductive performance of hormonally-treated anestrous Awassi ewes. Animal Reproduction 3(3): 347-352.

Kumar KP, Bramhaiah KV, Naidu GV, Ekambaram B, Krishna NVV, Rajesh MM (2018) Synchronization of Nellore Jodipi ewes by different doses of PGF2 $\alpha$. Indian Journal Animal Research 52(3): 363-366.

Laliotis V, Vosniakou A, Zafrakas A, Lymberopoulos A, Alifakiotis T (1998) The effect of melatonin on lambing and litter size in milking 
ewes after advancing the breeding season with progestagen and PMSG followed by artificial insemination. Small Ruminant Research 31(1): 79-81.

Mellor DJ, Stafford KJ (2004) Animal welfare implications of neonatal mortality and morbidity in farm animals. The Veterinary Journal 168(2): 307-324.

Miljkovic V, Petrujkic T, Vujosevic J, Mrvos P, Mihajlovksi P, Predojevic M, Naumov N, Tanev D, Stanojevic T, Jovanovic V (1989) Contemporary aspects of physiology of reproduction and artificial insemination in small ruminants. Veterinarski Glasnik 43: 875-882.

Minitab (2014) Minitab for Windows, United States.

Mirzaei A, Mohebbi-Fani M, Omidi A, Boostani A, Nazifi S, Mahmoodian-Fard HR, Chahardahcherik M (2017) Progesterone concentration and lambing rate of Karakul ewes treated with prostaglandin and GnRH combined with the ram effect during breeding and non-breeding seasons. Theriogenology 100: 120-125.

Niasari-Naslaji A, Soukhtezari A (2005) Comparison between three estrus synchronization programs using pro-gestagens during the breeding season in the ewe. Pajouhesh- Sazandegi 65: 86-91.

Nowers CB, Coetzer WA, Morgenthal JC (1994) Effect of melatonin implants, flushing and teasing on the reproductive performance of spring-mated Dohne Merino ewes. South African Journal Animal Science 24(1): 22-26.

Öztürkler Y, Çolak A, Baykal A, Güven B (2003) Combined effect of a prostaglandin analogue and a progestagen treatment for 5 days on oestrus synchronisation in Tushin ewes. Indian Veterinary Journal 80: 917-920.

Sönmez R, Kaymakçı M (1987) Koyunlarda Döl Verimi. Ege Üniversitesi Ziraat Fakültesi Yayınları No: 404, İzmir.
Swelum AAA, Alowaimer AN, Abouheif MA (2015) Use of fluorogestone acetate sponges or controlled internal drug release for estrus synchronization in ewes: Effects of hormonal profiles and reproductive performance. Theriogenology 84(4): 498-503.

Ungerfeld R, Rubianes E (2002) Short term primings with different progestogen intravaginal devices (MAP, FGA and CIDR) for eCGestrous induction in anestrus ewes. Small Ruminant Research 46(1): 63-66.

Ülker H, Gökdal Ö, Aygün T, Karakuş F (2004) Karakaş ve Norduz koyunlarının temel üreme özellikleri bakımından karșılaştırılması. Yüzüncü Yıl Üniversitesi Tarım Bilimleri Dergisi 14(1): 59-63.

Wallace JM, Robinson JJ, Wigzell S, Aitken RP (1988) Effect of melatonin on the peripheral concentrations of LH and progesterone after oestrus, and on conception rate in ewes. Journal of Endocrinology 119(3): 523-530.

Wildeus S (2000) Current concepts in synchronization of estrus: sheep and goats. Journal of Animal Science 77: 1-14.

Yadi J, Moghaddam MF, Khalajzadeh S, Solati AA (2011) Comparison of estrus synchronization by PGF $2 \alpha$, CIDR and Sponge with PMSG in Kalkuhi Ewes on early anestrous season. International Conference on Asia Agriculture and Animal. IPCBEE (13) IACSIT Press, Singapoore.

Yaprak M, Korkmaz MK (2016) Effect of different oestrus synchronization methods on reproductive performance of Morkaraman (Redkaraman) sheep in laparoscopic artificial insemination program. Journal of Biotechnology 231: 21.

Yılmaz M (2017) Bazı koyun rrk ve tiplerinin kuzu üretim etkinliğinin belirlenmesi. Yüksek Lisans Tezi, Namık Kemal Üniversitesi Fen Bilimleri Enstitüsü, Zootekni Anabilim Dalı, Tekirdağ. 